\title{
JOSÉ CORREIA LEITE, EDUARDO DE OLIVEIRA, EDUARDO DE OLIVEIRA E OLIVEIRA - MILITANTES DO MOVIMENTO NEGRO DE SÃO PAULO NO SÉCULO XX
}

\author{
Ivair Augusto Alves dos Santos ${ }^{1}$
}

Resumo: Este texto pretende apresentar histórias da vida de intelectuais negros, que foram importantes no ativismo negro, na cidade de São Paulo, nos anos de 1980 e pouco conhecidos ou referenciados pelas gerações mais novas do movimento e da intelectualidade. A partir de Mário de Andrade, passamos pela trajetória de três intelectuais negros: José Correia Leite, Eduardo de Oliveira e Eduardo de Oliveira e Oliveira. São referências no século XX para a consolidação de um espaço de ativismo, transformado em propulsor das conquistas alcançadas nos anos seguintes.

Palavras-chave: Ativismo Negro; Intelectuais Negros; Histórias de Vida.

\section{JOSÉ CORREIA LEITE, EDUARDO DE OLIVEIRA, EDUARDO DE OLIVEIRA E OLIVEIRA - MILITANTS OF THE BLACK MOVEMENT OF SÃO PAULO IN THE 20TH CENTURY}

\begin{abstract}
This text intends to present the life stories of black intellectuals, who were important in the black activism, in the city of São Paulo in the 1980 and are little known or referenced by the younger generations of the movement and the intellectuality. From Mário de Andrade, we went through the trajectory of three black intellectuals: José Correia Leite, Eduardo de Oliveira and Eduardo de Oliveira e Oliveira. They are references in the twentieth century for the consolidation of a space of activism, transformed into the propeller of the achievements reached in the following years.
\end{abstract}

Key-words: Black Activism; Black Intellectuals; Life stories.

\section{JOSÉ CORREIA LEITE, EDUARDO DE OLIVEIRA, EDUARDO DE OLIVEIRA ET OLIVEIRA - MILITANTS DU MOUVEMENT NOIR DE SÃO PAULO AU XXE SIÈCLE}

Résumé: Ce texte a pour but de présenter les histoires de la vie des intellectuels noirs, qui ont joué un rôle important dans l'activisme noir, dans la ville de São Paulo dans les années 1980 et qui sont peu connus ou mentionnés par les jeunes générations du mouvement et de l'intellectualité. De Mário de Andrade, nous avons suivi la trajectoire de trois intellectuels noirs: José Correia Leite, Eduardo de Oliveira et Eduardo de Oliveira et Oliveira. Ce sont des références au XXe siècle pour la consolidation d'un espace d'activisme, transformé en propulseur des acquis des années suivantes.

Mots-clés: Activisme Noir; Intellectuels Noirs; Histoires de Vie.

JOSÉ CORREIA LEITE, EDUARDO DE OLIVEIRA, EDUARDO DE OLIVEIRA E OLIVEIRA - MILITANTES DEL MOVIMIENTO NEGRO DE SÃO PAULO EN EL SIGLO XX

\footnotetext{
${ }^{1}$ Executivo Público da Secretaria de Saúde de São Paulo. Professor de Introdução à Sociologia na UnB. E-mail: ivairs@gmail.com
}

Revista da ABPN • v. 11, Ed. Especial - Caderno Temático: Raça Negra e Educação 30 anos depois: e agora, do que mais precisamos falar? • abril de 2019, p.351-371

DOI 10.31418/2177-2770.2019.v11.c.1.p351-371 
Resumen: Este texto pretende presentar historias da la vida de intelectuales negros, que fueran importantes em el activismo negro, en la ciudad de São Paulo, en los anõs 1980 y poco conocidos o referenciados por las generaciones más jóvenes del movimiento y de la intelectualidad. A partir de Mário de Andrade, pasamos por la trayectoria de tres intelectuales negros: José Correia Leite, Eduardo de Oliveira y Eduardo de Oliveira e Oliveira. Son referencias en el siglo XX para la consolidación de un espacio de activismo, transformado en propulsor de las conquistas alcanzadas en los años siguientes.

Palabras-clave: Activismo Negro; Intelectuales Negros; Histórias de Vida.

O que eu sei é da existência das pesquisas que os brancos fizeram a respeito do problema racial. Infelizmente, no começo o negro era estudado como cobaia, doente. Era estudado por médicos como Nina Rodrigues, Arthur Ramos. Depois veio o festejado livro Casa Grande e Senzala, de Gilberto Freire - mais casa grande do que senzala. Mais tarde com Roger Bastide e Florestan Fernandes, o problema foi levado para o campo da sociologia. Mas isso tudo foi feito pelo branco.

[...] houve um tempo que existia uma coletividade negra, lá pelas primeiras décadas deste século (XX). Quando aparecia, no entanto, um indivíduo bemintencionado, com a ideia de fazer a aproximação, de promover a solidariedade para o levantamento da raça (ou como se dizia na época: da classe), se ele tivesse um certo apoio. Logo aparecia outro para fazer a mesma coisa ou então para combatê-lo. Não sei porque o negro não teve uma confiança no outro.

[...] esse meu depoimento espero que possa ser um ponto de referência para as pessoas interessadas em conhecer o que houve, o que fez uma minoria preocupada em apontar erros e injustiças da tal abolição da escravatura. Só o negro pode advogar essa questão. As consequências ainda estão aí. É uma carga muito forte e negativa dos 400 anos de retardamento que não é só físico, mas também mental e espiritual. Então um grupo mais ou menos esclarecido entendia que o negro devia ir a campo para se conscientizar e combater com a mesma arma o branco: cultura e instrução, o que o negro não tinha nem se preocupava em ter, e nós tínhamos que enfrentar também o meio branco. Para uma boa parte dele, o negro estava muito bem aqui no Brasil, tinha liberdade para morrer de beber cachaça, de tuberculose [...]. De maneira geral, os brancos viam no negro uma raça inferior, achavam que nós não tínhamos necessidade de subir, e que o mínimo para a sobrevivência era o bastante.

[...] O negro era aceito por bondade, por caridade. Quando um branco dava um sorriso para o negro, o negro tinha que aceitar aquilo como favor. Se ele gostava do negro, o negro tinha que aceitar aquilo como um favor. É um dos preconceitos mais safados que pode haver. (Leite, 1992:17-21)

Na celebração dos 30 anos do Seminário Raça Negra e Educação, promovido pela Fundação Carlos Chagas, Associação Brasileira de Pesquisadores Negros e pelo Núcleo de Estudos Afro-brasileiros da Universidade Federal de São Paulo (Unifesp), 
fiz uma breve apresentação sobre a vida de intelectuais negros que foram importantes para o ativismo em São Paulo, ao longo das décadas até 1980.

Ao decidir escrever sobre alguns militantes que atuaram no século $\mathrm{XX}$, fui motivado pela necessidade de resgatar a memória de homens e mulheres negros que trabalharam em condições adversas contra o racismo. As gerações mais novas pouco citam ou registram a contribuição dessas pessoas.

Participo frequentemente de palestras, seminários e oficinas e constato pouco conhecimento sobre a história de ativistas e militantes do movimento negro brasileiro. Homens e mulheres negras que continuam invisíveis na história recente deste País.

Este trabalho é parte de um projeto de resgate da memória de homens e mulheres que participaram do movimento negro brasileiro.

Inicio recuperando um ensaio do escritor Mario de Andrade, denominado "Estudos sobre o negro", que foi apresentado no cinquentenário da Abolição, organizado pelo próprio Mario de Andrade, como diretor do Departamento de Cultura da Municipalidade de São Paulo, em maio de 1938.

No último parágrafo do texto, o autor tece uma crítica aos intelectuais negros da época das celebrações do cinquentenário da Abolição:

O que senti nas comemorações é que o negro se contenta em alcançar um posto de destaque intelectual entre os do seu meio ainda culturalmente menos apreciável. Nenhum se dedicou a uma obra de fôlego, nenhum a uma obra paciente de cultura, nenhum a uma obra de igualdade. [...] E é incontestável que na maior data negra do Brasil, os intelectuais negros não quiseram se igualar como era possível, e não quiseram vencer, como deviam.

[...] Aproveito este momento que não pretende ser de louvações inúteis para concitar os negros à coragem de maiores esforços. É preciso, pelo menos por enquanto, que eles não se esqueçam da pesada cor que têm. É preciso que eles se redimam do simbolismo das cores que levou a cor branca a ser o bem e a preta a ser o mal. Porque não basta abolir o preconceito de cor, é preciso justificar essa abolição. É só esforço próprio, tenacidade, o gozo e as volúpias de tais batalhas é que levarão os negros a esta vitória perfeita de serem homens como quaisquer outros. (Grillo:2010:60)

Este texto traz um conjunto de dilemas que ativistas e intelectuais negros enfrentaram ao longo do século XX. A busca pela realização de trabalhos de pesquisa, estudos que dessem conta da história de luta dos ativistas negros. A cobrança por 
trabalhos de fôlego nem sempre foi justa com as condições disponíveis para quem se dispunha a denunciar o racismo sofrido pelos negros no País.

A sociedade, nas primeiras décadas pós abolição, manteve estruturas muito rígidas, com poucas oportunidades de acesso à escolaridade para negros. Soma-se a isso a inexistência de espaços de sociabilidade para negros no universo dos brancos.

Durante o século XX convivemos com a ideia de um país sem racismo, sem discriminação racial, onde todos estavam em plena igualdade racial. Aqueles que ousavam discordar foram marginalizados, ignorados e esquecidos.

Fiz o levantamento de informações a partir de publicações desses intelectuais, de anotações e depoimentos de ativistas que estão em jornais da imprensa negra do início do século, em revistas, jornais e livros publicados em editoras pequenas, com edições do próprio autor. Neste trabalho me detenho a relatar os intelectuais José Correia Leite, Eduardo de Oliveira e Eduardo de Oliveira e Oliveira.

No texto de Mario de Andrade, há uma cobrança aos ativistas e intelectuais negros por um comportamento mais cuidadoso, criterioso, um trabalho de fôlego, que tivesse reconhecimento da academia, dos membros da intelectualidade do establishment e reafirmasse, pela obra, o valor e papel do negro na cultura brasileira. A pesquisa por uma teoria que pudesse servir de orientação para aqueles que lutam contra a discriminação racial no Brasil.

A narrativa que pretendo escrever conta a história de várias gerações de negros brasileiros e de como eles deixaram um legado de costumes, comportamentos, atitudes e exemplos por meio de narrativas.

São histórias em que os homens negros aprenderam que igualdade de oportunidades não existia, as chances de um homem negro nunca são iguais. Ensina-se que a privação, o sacrifício, as dores fazem parte de ser negro.

Homens que aprenderam que se deve lutar e não menosprezar as pequenas vitórias do quotidiano.

Nossa história começa no início do século XX, quando os negros na cidade de São Paulo dispunham de raros espaços de convivência, em um tempo em que não havia televisão e o rádio era um artigo de luxo em poucas casas. A comunicação entre 
as pessoas era feita por jornais, revistas, material impresso em linotipia. Estamos falando da cidade de São Paulo.

O trabalho destinado aos negros era duro, serviçal, uns poucos conseguiam trabalhar na indústria; aprender a ler e escrever era muito difícil. $\mathrm{O}$ analfabetismo era grande. Ser operário brasileiro em uma fábrica dominada por estrangeiros era um luxo.

Na cidade de São Paulo havia uns casarões, com porões com pouca iluminação e quase nenhuma circulação de ar. No bairro do Bexiga, próximo ao centro, havia muitos cortiços onde famílias dividiam o mesmo tanque, o mesmo banheiro.

Correia Leite nasceu na Rua 24 de maio. Em 1900, ali era uma zona residencial da pequena cidade de São Paulo e não o centro de comércio como é hoje. Sua mãe era negra, doméstica, muito lutadora, mas não o podia manter. Ela tinha de deixá-lo na casa dos outros para poder trabalhar. Então sempre viveu maltratado. Nunca teve aquele afeto materno. Na Cidade da Garoa, passou muita fome. Procurou ajuda para aprender a ler, até trabalhar de graça. Seu desejo na infância era um dia poder ir à escola e ler como os outros meninos.

Nas primeiras décadas do século XX, o 13 de maio de 1888, data da abolição da escravidão, estava muito próximo da escravidão, de modo que muitas pessoas eram filhas e netas de escravo e tinham presente na memória a realidade da escravidão. Sempre é bom registrar essa questão de o negro ter saído da noite de três séculos de escravidão e caído na marginalidade.

A geração de Correia Leite estava muito próxima de 1888. Depois daqueles horrores todos, houve desamparo e nenhum apoio para aqueles que haviam sido escravizados. Os negros tinham que conviver com a sombra da senzala na frente. $\mathrm{O}$ sentimento do desamparo, de abandono, de preconceito e injustiças acompanhava a comunidade negra em São Paulo.

Em seu depoimento sobre o mercado de trabalho naqueles tempos do início do século, Correia Leite disse o seguinte:

Os que estavam 'lá em cima' eram os nossos 'protetores', advogados, fazendeiros... Esses tratavam a gente ainda como descendentes de escravos ou filhos de escravos. Eu via que eles tratavam o negro com aquela mesma empáfia, com o mesmo ranço escravocrata. Por outro lado, no meio proletário, negro era visto não de igual para igual, mas sempre com qualquer sentido de 
inferioridade. Eu me lembro que se um negro chegasse na construção civil, vamos supor, se dissesse que era pedreiro, ele tinha de provar que era "bom pedreiro". Eles nunca confiavam. O negro tinha de se sujeitar a um determinado tempo de prova. E sempre o ordenado dele era inferior, porque não havia a lei do salário mínimo. Quando um branco ia contratar um negro para ser empregado dele, a primeira coisa que ele queria saber é se ele tratavase de um bêbado.

- Não, eu não bebo.

- Então solta um bafo aí. (Leite,1992, p. 55)

O acesso ao trabalho para os negros era difícil. Correia Leite viveu com imigrantes italianos. Trabalhou como ajudante, entregador de marmita, carregador e ficou desempregado diversas vezes. Uma realidade de muitos negros.

Para a comunidade negra, os bailes tiveram uma grande importância para a sua socialização; eles ocorriam aos domingos e até na segunda feira. Aos domingos começavam às 15 horas e avançavam para depois da meia noite. Foi num desses bailes que Correia Leite se aproximou da comunidade negra. Tinha 22 anos.

Essa aproximação das atividades das associações negras mudou sua vida, pois pôde reencontrar amigos de infância, como Jayme de Aguiar, que o ensinou a ler e escrever.

Um dia reencontrei o Jayme de Aguiar. Já não era mais aquele moleque. Dei com ele no baile. Ele fez uma festa comigo. Era acostumado a frequentar bailes de sociedades. [...]

Um dia ele me disse:

- Zé, você não se ofende, mas eu posso te dar umas aulas de português para ajudar a melhorar?

Eu respondi prontamente:

- Me ofender? Não. Você me faz um grande favor. É só marcar.

Ele marcou o dia e passou a ir lá onde eu morava, no Bixiga, no porão da casa de uns italianos. Ele ia duas vezes por semana e me dava aulas de matemática e português. (Leite, 1992, p. 29)

Essa amizade com Jayme de Aguiar acabou gerando a ideia de fundarem um jornal, em 1924. O nome dado foi Clarim d'Alvorada, que no início era um jornal de notícias literárias. Antes do Clarim, havia um famoso jornal em Campinas, o Getulino. 
O trabalho de manter um jornal era feito por pessoas abnegadas, e tinham de enfrentar tantas dificuldades e oposições a essas iniciativas que um jornal durava dois ou três números. Outros tiveram uma vida longa como o Kosmos, o Menelick, o Alfinete. A principal dificuldade era financeira.

O Clarim d'Alvorada anunciava festas, bailes e casamentos e acabava sendo distribuído e sendo vendido nessas atividades.

O Clarim também começou a publicar traduções de notícias dos Estados Unidos, artigos de Marcus Garvey e de outros negros, bem como teses de congressos que ocorriam nos Estados Unidos e que se opunham à cultura do branco, aos ensinamentos do branco.

O ano de 1930 começou uma nova fase do movimento negro, segundo Correia Leite, com a criação da organização da Frente Negra Brasileira, que foi criada em 1931:

Aí começou uma outra fase do movimento negro, a mais agitada e mais forte, porque foi quando o negro teve uma motivação para aglutinar. E como o negro tinha que enfrentar a crise econômica, que vinha de 1929, envolvendo os Estados Unidos, houve uma pressão maior para que se resolvessem os problemas. Aqui no Brasil a "bomba tinha estourado mais pro lado dos negros, o subempregado. (Leite, 1992, p. 93)

Correia Leite se integrou à Frente Negra Brasileira, foi membro do Conselho da entidade, mas, por desacordo com as ideias do restauro da monarquia, e por acreditar que havia uma mistura dos ideais políticos e com o movimento negro, Ele optou por se afastar da Frente Negra Brasileira. Correia Leite tinha convicções políticas republicanas, democráticas e socialistas, que o afastava dos objetivos da Frente negra Brasileira.

Correia Leite reconheceu a importância e o papel da Frente Negra Brasileira e introduziu novas atividades, de arrecadação de fundos e procurou se expandir pelo país.

O trabalho com o Clarim d'Alvorada continuou até ser pensado em se montar uma cooperativa, mas, por questões burocráticas, acabaram formando uma sociedade cooperadora. A situação para se manter o jornal sempre foi muito difícil, o trabalho de 
tipografia era realizado por Correia Leite e por Henrique Cunha. A oficina era na casa de Correia Leite, e para os artigos mais longos se contratava o trabalho de linotipia.

Correia Leite, junto com a juventude negra da época, em $1^{\circ}$ de julho de 1932 , fundou o Clube Negro Cultura Social, criado dias antes da Revolução de 32, momento difícil pois diversos jovens foram mobilizados para participar da revolução.

A situação pegou fogo, estourou, teve que estourar a revolução, o que ficou ruim para a Frente Negra Brasileira. Ela era abertamente contra o Movimento Constitucionalista. Acabou ficando como uma entidade suspeita. E começou a correr um boato de que havia uma carta secreta em que o governador Pedro Toledo, para que se tomasse muito cuidado na aceitação de negros para participar da revolução. (Leite, 1992, p. 103-104)

O Clube Negro Cultura Social tornou-se um espaço para jovens que praticavam esportes, participando de torneios de corridas de rua e uma preocupação com uma biblioteca. Como todas as associações daquela época, dependia de abnegados, que tinham que dispor de seu tempo e dinheiro para mantê-los.

Em 1937, Leite entrou na Prefeitura Municipal de São Paulo, por insistência de um amigo, entrou como operário, depois tornou-se ajudante de campo para a engenharia. Nesse mesmo ano, Getúlio Vargas deu um golpe, instalando o Estado Novo, o que levou ao fechamento dos partidos políticos e de determinadas entidades, e a Frente Negra Brasileira foi uma delas.

O Estado Novo foi o nome que Getúlio Vargas deu à ditadura. Terminou com todos os movimentos de lutas sociais do negro porque eram considerados luta de classe. Aí o Movimento Negro parou e o Clube Negro Cultura e Social, que participou dos festejos do Cinquentenário da Abolição da Escravidão, em 1938, também foi obrigado a fechar. Mas o Borba conseguiu dialogar com o departamento de polícia política e foi permitido que o clube continuasse, apenas como uma entidade cultural não negra, tanto que teve que tirar a palavra negro. (Leite, 1992, p. 137)

O período de censura contra os movimentos sociais durou até o fim da Segunda Guerra Mundial. Já em 1945 iniciou-se a mobilização dos negros do Rio de Janeiro e depois em São Paulo, para influenciar na elaboração da nova Constituição. Em São Paulo foi criada a Associação dos Negros Brasileiros.

A segunda Guerra Mundial trouxe a mudança de comportamento no uso da palavra "racismo", que passou a ser incorporada: 
Essa palavra "racismo", depois da guerra, veio reforçar aquela situação muito chata: o negro toda vez que queria falar dos seus problemas era chamado de racista. $[\ldots]$

Eu me lembro que quando o Abdias montou a peça Sortilégio ele foi também acusado por toda a imprensa carioca de racista. Teve também os que o defenderam como Nelson Rodrigues e outros. (Leite, 1992, p. 158)

Correia Leite dedicou sua vida a publicar jornais e a criar entidades negras que discutissem ideias, por sua contribuição e liderança que foi realizada no Brasil sobre as relações raciais. Colaborou com Roger Bastide, Florestan Fernandes e Renato Jardim Moreira, que culminou com um estudo substancioso publicado em 1955, com o título de "Relações entre negros e brancos em São Paulo" (Bastide, Roger; Fernandes, Florestan, (1955).

Em 1956, Correia Leite é conclamado a participar de mais uma entidade de propaganda em defesa dos valores negros, a Associação Cultural do Negro. Essa entidade foi o espaço onde surgiram grandes intelectuais negros, como o escritor músico Oswaldo de Camargo, a atriz Nair Araújo, Américo Orlando e o sociólogo Eduardo de Oliveira e Oliveira.

Correia Leite continuou a ser uma referência para muitas gerações como um militante que dedica a sua vida a promoção dos valores negros na sociedade brasileira. A preocupação era reunir, unir as lideranças negras em defesa das reivindicações da população negra contra as injustiças.

Nesse processo de resgate, um outro representante que também se dedicou a trabalhar pela valorização da cultura negra foi o escritor Eduardo de Oliveira.

\section{EDUARDO DE OLIVEIRA}

Um criador, um poeta com muita energia. Conheci-o na década de 1960, quando lançava mais um livro de poesia. Um sorriso largo, sempre otimista em relação à vida. $\mathrm{O}$ cabelo encaracolado, negro. Andar firme e apressado, alegre, sempre com uma observação simpática. Sempre carregando livros e uma mala que devia pesava muito. Com uma visão alegre diante do futuro e uma batalha pela frente.

Nos anos $1970 \mathrm{eu}$, estudante, depois de reuniões, me encontrava com ele na Rua 24 de maio, na sede da União Brasileira de Escritores. As reuniões eram 
demoradas e os ônibus eram raros depois de certa hora da noite. Reuniões que terminavam com um lanche em dos restaurantes da 24 de maio, que ele sempre acabava pagando. Ninguém trabalhava no grupo.

A União Brasileira de Escritores era o ponto de encontro, onde podia-se estar e conversar com o professor Eduardo de Oliveira.

\section{A MÃE}

Eduardo conviveu muito pouco tempo com sua mãe, que foi uma ausência sentida durante sua vida inteira. Banzo (Oliveira, 1964) começa com o soneto "Pátria dos nove sonhos"

Não sei se choro a mãe que nunca tive

Ou se lamento a irmã desconhecida, Cobrindo-me de prantos, já que a vida

É apenas uma ausência em meu declive

A mãe que habita em mim, na alma inclusive

- Pátria dos nove sonhos, mas, perdida -

Partiu cedo demais e, na partida

Deixou-me esta tristeza, que ainda vive.

Quando nasci, levaram-na de mim; Em sendo eu luz, tornei-me um sol cadente...

Eu era começo e fui seu fim,

Sepultando-a, talvez, dentro, em meu eu,

Para senti-la mais, como se sente A saudade de alguém que já morreu.

Em outra estrofe, a lembrança da mãe é citada no poema "Balada das mãos pedintes" (Oliveira, 1964):

Estendi minhas mãos à minha mãe ignota E ela deixou cair em meus lábios um conforto diferente

No livro Túnica de Ébano (Oliveira, 1980), há uma trova que sintetiza a dor e a tristeza de não ter mãe:

Não ter mãe! Transpor os mares

Da vida sem ter ninguém.

Eis o pesar dos pesares,

De quem só pesares tem. 


\section{SÃO PAULO, A CIDADE EM QUE VIVEU EDUARDO}

\section{Paulicéia}

Minha amada Paulicéia, Tão selvagem, tão gentil:

És a minha flor plebeia Nos vergéis do meu Brasil!

Cogumelo andante

Procedo da miséria mais pungente Onde o sol da alegria nunca chega.

Eu nasci pelo chão das ruas

\section{O grande esquecimento}

Na minha capelinha, ao lado de mil prédios Eu vi Nossa Senhora, a Santa dos Remédios.

É um bairro muito triste, sujo, abandonado, Igual a muitos outros que existem por aí

Sua população é só de gente humilde

Com seu trabalho e com seu suor Constroem muita riqueza, constroem muito Conforto que seus tristes augúrios Nunca tiveram e nunca sonhar ter

\section{A NEGRITUDE NA POESIA DE EDUARDO DE OLIVEIRA}

Ao ler seus poemas no livro Banzo (Oliveira, 1964), encontram-se belas passagens líricas e eternas de negritude, onde nos deparamos com reivindicações transformadas em versos. Diz que a África não é uma África sem memórias, sem passado.

Banzo

Eu sei, eu sei que sou um pedaço d'África

Pendurado na noite do meu povo, Trago em meu corpo a marca das chibatas

Como rubros degraus feitos de carne Iam buscar as brenhas do futuro

Eu sei, eu sei sou um pedaço d'África Pendurado na noite do meu povo.

Eu vi nascer mil civilizações Erguidas pelos meus potentes braços; Mil chicotes abriram na minh'alma Um deserto de dor e de descrença 


\section{Das piras do Kilimanjaro}

Eu ouço a voz do meu povo A gritar justiça no meu sangue É um lamento fundo e angustiado

Que ninguém quer ouvir

$[\ldots]$

O negro hoje, já sabe o judô do estrangeiro

Que o explora e mandar aos diabos os colonialistas A África hoje é um solo em erupção. Por isso o Kilimanjaro

Desce em lavas candentes como clangor de Justiça e de liberdade por que aspira o meu povo. (Oliveira,1968, p. 100)

Tumbeiros do além Eu sou um pedaço d'África Jogado no chão do mundo

Tumbeiros malditos Tumbeiros do Nilo Tumbeiros do Saara Tumbeiros dos Caos Tumbeiros do Além

\section{Lamento negro}

Eu sinto em minhas veias

$\mathrm{O}$ grito dos cafezais Enxergo em minhas mãos a sombras dos meus irmãos vergastado pelo chicote dos senhores da terra. Aqueles que carregam o Brasil nas costas Não tem túmulos Nem legendas; Seu sono não é velado ... Seu nome ninguém conhece (Oliveira, 1968, p. 105)

Volúpias negras

Bocas negras Negras vozes Que tem fome de justiça e de música.

Almas negras Negras preces

Que se prolongam nem mistério de sombras de infinito

\section{A LUTA PELA IMORTALIDADE}


Em um tempo em que o negro era invisível, ele lutou contra a invisibilidade e lutou pela eternidade. Um conceito religioso de quem acredita num ideal supremo, metafísico, que conseguirá romper todas as amarras.

No poema "Não mais quero morrer":

Eu não quero morrer! É muito cedo!

A ventura, afinal, bateu-me à porta E revelou-me, há pouco, o seu segredo.

O ideal levou-me ao templo da beleza, E eu não mais sinto que a existência é morta Que, se eu morrer, quem morre é a natureza.

Eduardo não queria morrer. Em vida, vivia gritando sua poesia. "Eu não quero morrer".

A morte, quando aparece, Lembra canção de ninar, Que, alegre, a gente adormece,

Para não mais acordar!

614

Minha alma parte, sem norte Numa olímpica corrida, Montando o corcel da morte... Mas sempre em busca da vida!

\section{EDUARDO DE OLIVEIRA E OLIVEIRA}

Sou um homem invisível. Não, não sou um fantasma como os que assombravam Edgar Allan Poe; nem um desses ectoplasmas de filme de Hollywood. Sou um homem de substância, de carne e osso, fibras e líquidos talvez se possa até dizer que possuo uma mente. Sou invisível, compreendam, simplesmente porque as pessoas se recusam a me ver. Tal como essas cabeças sem corpo que às vezes são exibidas nos mafuás de circo; estou, por assim dizer, cercado de espelhos de vidro duro e deformante. Quem se aproxima de mim vê apenas o que me cerca, a si mesmo, ou os inventos de sua própria imaginação - na verdade, tudo e qualquer coisa, menos eu. (Ellison, 1990:25) 
Assim começa o prólogo de Homem invisível, romance lançado em 1952 com grande sucesso por Ralph Ellison (Marco Zero, 1990).

Na década de 1970, conheci o professor Eduardo de Oliveira e Oliveira, um negro intelectual, que vivia em São Paulo e dedicava-se ao trabalho de formação de jovens negros, por meio de atividades culturais como teatro, literatura, debates, seminários e grandes e animadas conversas. Eduardo me impressionava por sua capacidade de comunicação, inteligência rápida e instigante.

Era negro, homossexual, intelectual e de esquerda, e denunciava sistematicamente o racismo da sociedade paulistana, pelos jornais e debates nas universidades brasileiras.

Ao visitar a Unidade Especial de Memória e Informação da Universidade Federal de São Carlos, acessei a Coleção Eduardo Oliveira e Oliveira, e fui tomado por uma emoção em poder rever documentos, panfletos, livros, recortes de jornais de um período que vivi e conheci muito daqueles personagens.

Eduardo Oliveira e Oliveira nasceu no Rio de Janeiro, pai de origem portuguesa, sindicalista do setor portuário, e mãe negra que trabalhava como empregada doméstica na casa do funcionário da embaixada francesa.

Estudou nos melhores colégios da cidade, cursou música no antigo Liceu de Ofícios e Artes, logo cedo aprendeu a falar francês e chegou até a atuar num grupo francês que excursionava pela cidade do Rio de Janeiro. Deixou o Rio de Janeiro depois de desavenças na família.

Em São Paulo conseguiu emprego na empresa Metal Leve, mas logo perseguiu o sonho de ser sociólogo e entrou na Faculdade de Filosofia e Letras da Universidade de São Paulo (USP), em 1960, o que o torna contemporâneo de professores e estudiosos que irão marcar a intelectualidade brasileira e dominar a oposição política durante o regime militar.

Um dos aspectos que me chamaram a atenção foi sua preocupação em discutir com a literatura americana dos anos de 1960 e 1970 a ideia de uma sociologia negra, uma análise crítica sobre a sociologia que era produzida na época, em que o negro era 
visto como objeto de estudo, gerando descontentamento sobre a produção científica que retratava a situação do negro no Brasil.

Intelectuais negros se debruçaram sobre a possibilidade da criação de uma sociologia negra que pudesse surgir a partir do negro, como sujeito de uma sociedade de classes, que é protagonista de suas ações. Uma ciência que pudesse ser levada a práxis na defesa e promoção dos direitos do negro no Brasil.

Na década de 1970, eram raros os intelectuais negros com visibilidade e que se propunham a dialogar com a militante juventude negra de São Paulo: Clóvis Moura, Eduardo de Oliveira e Oliveira, Abdias do Nascimento, Lélia Gonzalez e Joel Rufino eram alguns destes. Havia poucos espaços públicos em que se podia discutir a temática de relações raciais. Vivíamos o período do regime militar com muita repressão.

Haroldo Costa, em seu livro Fala crioulo, diz que

[...] cada vez que há um endurecimento um fechamento político, o negro é atingido diretamente porque todas as suas reivindicações particulares, a exposição de suas ânsias, a valorização de sua história desde que não sejam feitas segundo os ditames oficiais, cheiram à contestação subversiva. (Costa, 1982)

Os movimentos negros se aliaram às forças democráticas na luta contra o regime militar, o autoritarismo, a carestia e por isso passaram a ser vigiados pelo sistema de repressão. Os posicionamentos do movimento negro contra as políticas formuladas e implementas pelo regime levaram a comunidade de informação e segurança a identificar as entidades negras como "subversivas" (Kossling, 2007, p. $38)$.

A literatura negra em São Paulo, na época, tinha na figura de escritores como Oswaldo de Camargo sua figura de maior expressão. Em 1972, ocorreu o lançamento do livro Carro do Exito, na Rua Augusta, na livraria de Nair Araújo, uma antiga militante do movimento negro. É um livro representante da literatura negra da época, uma obra de estreia em contos que registra o momento de mudança do movimento negro na promoção de manifestações da juventude negra.

Um dos espaços públicos, de local de encontros da juventude negra era a Biblioteca Mario de Andrade, localizada no centro da cidade de São Paulo. Foi nesse lugar que a equipe de Florestan Fernandes e Roger Bastide realizou os seminários 
junto à comunidade negra para a célebre pesquisa da Unesco, sobre as relações raciais em São Paulo, em 1955.

Entre alguns intelectuais negros vivia-se um sentimento de ansiedade que perpassa os seus escritos, como a de uma busca incessante por uma construção teórica que inspirasse a todos na luta de como enfrentar o racismo que estava presente no cotidiano de todos os negros brasileiros.

Eduardo de Oliveira e Oliveira foi um desses intelectuais que dominou o cenário nos anos de 1970, realizando seminários, oficinas, e sendo precursor da realização de muitos eventos na cidade de São Paulo. Foi tradutor da obra de Roger Bastide, publicou muito pouco, mesmo assim deixou importantes reflexões. E também foi dramaturgo. Como dramaturgo, trabalhou em parceria com Tereza Santos e criaram o espetáculo "E Agora... falamos Nós".

"E agora... falamos nós" foi vista por estudantes secundaristas, universitários, alguns amigos e parentes do elenco, além dos ativistas e artistas negros. Sua maior e melhor crítica pode ser encontrada na cobertura realizada pelo jornal Bondinho, periódico da chamada imprensa alternativa, interessada em produção cultural. Do público, um jovem registrou suas impressões sobre a montagem e a relevância dela para seu interesse político: “A peça 'E agora... falamos nós' foi como uma descarga elétrica na minha mente, a primeira vez que a questão racial me tocou a fundo", disse mais tarde Astrogildo Esteves, em depoimento para a imprensa alternativa paulista. Provavelmente esse espetáculo foi o evento mais bem-sucedido do Centro de Cultura e Arte Negra (Cecan), entidade idealizada e criada por Thereza, em 1971, com a finalidade de abrigar os projetos culturais do grupo negro que se formava no início daquela década.

Eduardo de Oliveira e Oliveira era um observador e analista atento aos fatos e, principalmente quando se tratava de discriminação racial, frequentemente escrevia artigos ou cartas para os jornais. Ele fazia uma dobradinha com o escritor Oswaldo de Camargo, que era responsável pelo setor de Cartas do jornal O Estado de São Paulo e Jornal da Tarde. 
A seguir reproduzimos uma das cartas, publicada no Jornal da Tarde, p. 4, em

15 de maio de 1975, e foi tirada do texto de Gilda Melo de Souza, que presta homenagem a Eduardo de Oliveira e Oliveira.

Ele começa citando trecho de carta de outro leitor, publicada anteriormente, e em seguida faz seu comentário, ao mesmo tempo irônico e amargo:

Agora um pormenor; o fator principal que deu ensejo ao episódio é de fácil explicação: as três pessoas que viajavam no veículo, incluindo a mim, eram 'cidadãos de cor' e, lamentavelmente, na mentalidade da maioria dos policiais, 'negros' em um automóvel, automaticamente $\mathrm{O}$ veículo tem que ser roubado [...] (A. Amaral, Capital, JT de 2/5/75.)

Sr.: "Li a carta que um jovem bacharel negro mandou ao JT, comentando sua perseguição pela polícia por estar guiando um carro que, provavelmente, não condizia com sua cor.

No dia 5 de maio, fomos ao Edifício Queen Mary, à rua Visconde de Ouro Preto, $\mathrm{n}^{\circ}$ 51, onde devíamos ir ao apartamento $\mathrm{n} .{ }^{\circ} 101$, quando fomos interpelados pelo porteiro, que exigiu que tomássemos o elevador de serviço. Alegamos que íamos na qualidade de visita, quando fomos informados pelo mesmo porteiro de que 'eles' tinham dado ordem de assim proceder. Isto é, negro pelos fundos.

Calculamos que 'eles' devem ser a administradora. No momento, subia no elevador uma senhora residente no prédio, que disse ser espanhola, que não só viu toda nossa argumentação como pareceu surpresa com o que via. Estávamos ao que acreditamos, convenientemente apresentáveis. Vestíamos uma suéter Bremer, comprada em Londres; calças de gabardine e sapatos comprados em Nova York (em Barney's, que agora é muito in) e uma bolsa a tiracolo de Roger-Gallet, de Paris (diga-se, a propósito, que reputamos os produtos brasileiros de moda masculina não só de péssima qualidade como vulgares), e convenientemente barbeados. Enfim, um negro de alma branca! Perguntamos: não seria melhor institucionalizar um tipo de roupa para negros que se destinam à porta da frente e outro tipo àqueles que se destinam à porta dos fundos?

(Eu, por mim, entro por qualquer porta, mas não quero que me discriminem a priori.) Estamos chegando dos Estados Unidos, onde fomos convidados, na qualidade de sociólogo, tendo circulado de Washington a Chicago, de São Francisco a Santa Fé; cruzamos o Estado de Mississippi, estivemos em Tennessee, Flórida, e coisa como esta jamais nos aconteceu. Nem agora nem em nenhuma das vezes em que lá estivemos anteriormente. As vezes que isto nos tem acontecido em São Paulo já passam da conta e paciência, e, se fazemos esta denúncia agora, é com o único propósito de colaborar com $\mathrm{S}$. Exa. O presidente da República, que se tem mostrado empenhado em questionar este tipo de coisas." Eduardo de Oliveira e Oliveira, Capital. (Souza, 1981, p. 68-71.)

Eduardo de Oliveira e Oliveira escreveu um artigo na revista Argumento publicação mensal de cultura da Editora Paz e Terra, que teve apenas quatro números publicados durante o ano de 1973 e início de 1974, sendo retirada de circulação pela 
ditadura. Através do slogan "Contra fato há argumento", anunciava-se como um meio de resistência ao regime então vigente no País.

O grupo que constituía a Argumento era formado por Barbosa Lima Sobrinho (Diretor), Antonio Candido, Anatol Rosenfeld, Celso Furtado, Fernando Henrique Cardoso, Francisco Corrêa Weffort, Luciano Martins e Paulo Emílio Salles Gomes (Comissão de Redação). Destaca-se ainda a colaboração dos críticos literários: Roberto Schwarz, Ángel Rama, João Luiz Lafetá e Davi Arrigucci Junior. Ser convidado a publicar mostrava o grande prestígio de que gozava o professor Eduardo.

Eduardo escreveu o artigo "O mulato um obstáculo epistemológico", onde comentava uma publicação de Carl N. Degler sobre a realidade das relações raciais no Brasil:

Que as relações raciais são por definição relações de correção, podendo ou não ser antagônicos. Mas são sempre oposições polares preponderantemente entre negros e brancos, substituindo uma epiderme social que a regulamenta; e isto por mais amplo que seja o spectrum das cores como pode ser o caso do Brasil. Franz Fanon exemplifica isto muito bem quando diz, " eu sou escravo não da ideia que os outros tem de mim, mas de minha própria aparência [...] quando gostam de mim, eles dizem que gostam apesar de minha cor. Quando não gostam dizem que não é por causa de minha cor. De um jeito ou de outro, estou fechado num círculo infernal. Também no Brasil, para nós, as relações raciais são oposições polares, não sendo, porém, polares antagônicas. (Oliveira, 1974, p. 69)

Era um olhar de uma sociologia que não contemplava o negro como sujeito da história, embora fosse uma sociologia crítica sobre a realidade brasileira e até chegasse a reconhecer a existência do racismo, da discriminação racial, mas o negro como sujeito da história não existia, e muito menos um negro intelectual na academia.

Na 29a reunião da Sociedade Brasileira para o Progresso da Ciência, em 1977, Eduardo foi coordenador de um simpósio intitulado "Brasil negro". Foi a primeira vez na história da SBPC que houve uma mesa dedicada aos negros. Ele apresentou um trabalho com o título "De uma ciência Para e não tanto Sobre o negro".

O trabalho faz uma reflexão sobre o papel do intelectual negro, e questiona se um negro poderia ser reconhecido como um intelectual numa sociedade como a brasileira. Uma das preocupações era saber qual seria o papel que o intelectual negro 
deveria desempenhar, será que haveria um diferencial? Um compromisso diferente diante das barreiras que o negro enfrenta?

Primeiramente é preciso que ele tome conhecimento e consciência de seu grupo, sabendo que sua libertação social, cultural, política e econômica não será possível sem uma teoria das condições dessa libertação, isto é, sem uma ciência das formações sociais. Um intelectual negro deve ser solidário e ter a consciência do que é ser negro, e que não há saídas individualistas. É preciso reconhecer que não uma libertação possível sem uma ciência comprometida [...] a ideia de uma sociologia negra (ou historiografia, economia, antropologia negras etc....) Ela surge como uma reação e revolta contra o viés da 'sociologia principal' burguesa-liberal; como um passo positivo para o estabelecimento de definições básicas, conceitos e construções teóricas que utilizam as experiências e história dos afro-brasileiros.

Existe um fator fundamentalmente básico na abordagem do negro que tem que ser levado em consideração (e frequentemente não o é) para de configurá-lo de qualquer identidade com outros grupos como comumente se faz. Vieram involuntariamente, foram escravizados e subsequentemente tiveram garantida uma cidadania de segunda classe. Não podemos ser paralisados da mesma forma que os europeus, ou mesmo os judeus, como geralmente se tende de aproximar como problemática.

É preciso que evitemos que sejamos medidos por normas estranhas a nossa experiência, com o que evitaremos sermos sempre pensados e analisados como desvios.

Os cientistas negros- influenciados pessoalmente e intelectualmente por sua experiência de negros - devem estabelecer uma investida 'perceptiva', tentando conhecer os fenômenos a serem estudados como sujeito/objeto que são de suas abordagens. Convém também lembrar que a ciência que faz do negro um objeto de estudos jamais pensou que este objeto questionaria sua suposta 'objetividade' quando detivesse os instrumentos necessários para avaliá-la. Existe uma situação objetiva e um estado subjetivo diferentes pra brancos e negros.

O negro sofre uma imposição cultural na base de estandartes universais tradicionais, nos quais encontram-se implícitos a desvalorização de seus valores: uma ameaça à identidade negra individual e uma aplicação cruel e dogmática destes valores que são opressivos porque geralmente implicam em que os negros sejam sub-humanos.

Em que medida o 'intelectual negro' deve se libertar dos clichês relativos ao problema negro? Intelectual, lato-sensu, é um homem que contribui com ideias originais, novas descobertas e informações no conjunto já existente do conhecimento. Um 'intelectual negro' é uma espécie à parte. Nos ombros dele recai uma outra tarefa, a de descolonizar sua mente de maneira que possa guiar outros intelectuais e estudantes na procura da liberdade. $O$ branco não só distorceu e destruiu o desenvolvimento dos negros, como também se deseducou a si mesmo. Cumpre instruí-lo. (Oliveira, 1977) 
Apesar dos anos, o trabalho de Eduardo de Oliveira e Oliveira continua atual e nos levando a permanentes reflexões sobre o papel que o intelectual negro deve ocupar na sociedade brasileira.

\section{CONSIDERAÇÕES FINAIS}

O revisitar a obra desses três intelectuais negros, na celebração dos 30 anos do Seminário Raça Negra promovido na Fundação Carlos Chagas, é um resgate de pessoas que deram uma contribuição pessoal por meio de sua escrita e exemplos de vida.

Esse trabalho é parte de um projeto de pesquisa que pretende levantar a história recente de intelectuais negros que atuaram ao longo do século $\mathrm{XX}$, que contribuíram para as conquistas do movimento negro no século XXI.

Ao final desse artigo registro: para esse universo uma mulher Fúlvia Rosenberg, que foi fundamental para a realização do Seminário Raça Negra e Educação. Foi uma mulher brilhante por sua dedicação, seu envolvimento, desprendimento na luta feminina e a formação de gerações de pesquisadores negros. E também uma grande amiga, que faz muita falta.

\section{REFERÊNCIAS}

BASTIDE, Roger; FERNANDES, Florestan, eds. (1955), Relações Raciais entre Negros e Brancos em São Paulo. São Paulo: UNESCO/Anhembi..1955

COSTA, Haroldo. Fala crioulo - depoimentos. Rio de Janeiro: Record, 1982.

GRILLO, Angela Teodoro. Processo de criação do Estudos pretos, um inédito de Mario de Andrade. Dissertação (Mestrado em Literatura Brasileira) - Universidade de São Paulo, São Paulo, 2010.

ELLISON, Ralph. O homem invisível - São Paulo: Marco Zero, 1990

KOSSLING, Karin Sant'Anna. As lutas antirracistas de afrodescendentes sob a vigilância do DEOPS/SP (1964-1983) Dissertação (Mestrado em História social) - Universidade de São Paulo, São Paulo, 2007.

LEITE, José Correia. ...E disse o velho militante. Organização e textos Cuti. São Paulo: Secretaria Municipal de Cultura, 1992.

MOURA, Clóvis. Sociologia do negro brasileiro. São Paulo: Editora Ática, 1988. 
Paulo: Anita Garibaldi, 2014.

Rebeliões da Senzala: quilombos, insurreições e guerrilhas. 5. ed. São

OLIVEIRA, Eduardo. Túnica de Ébano - Sonetos e Trovas. Piracicaba/SP: Edição da Tribuna Piracicabana, 1980.

OLIVEIRA Eduardo. Evangelho da solidão. São Paulo: Cupolo, 1968.

. Banzo - Poesias. 2.ed. São Paulo: Obelisco, 1964.

OLIVEIRA, Eduardo de Oliveira e. Etnia e compromisso intelectual. Comunicação realizada na $3^{\text {a }}$ Semana do Negro no Instituto de Ciências Humanas e Filosofia da Universidade Federal Fluminense, 1977.

pp.65-74, jan, 1974

O mulato um obstáculo epistemológico. Revista Argumento, São Paulo, ano 1, n.3,

RIBEIRO, Djamila. O que é lugar de fala? Belo Horizonte: Letramento, 2017.

SOUZA, Gilda de Melo. Homenagem a Eduardo de Oliveirae Oliveira. Revista Novos Estudos, São Paulo, v. 1, n. 1, p. 68-71, dez. 1981. 